ARTICLE

\title{
Environmental sustainability is not worth pursuing unless it is achieved for ethical reasons
}

Fabio Zagonari (iD ${ }^{1 凶}$

\begin{abstract}
This paper analytically characterizes the four main environmental sustainability paradigms (i.e., WS, weak sustainability; AG, a-growth; DG, de-growth; and SS, strong sustainability) by introducing uncertainty about future preferences for consumption and future technologies. SS represents an ethical approach because of its maximum aversion to intergenerational inequality of resources, whereas DG depicts preference changes, AG depicts technology changes, and WS represents the reference paradigm without accounting for preference or technology changes. By comparing the costs and benefits of these paradigms, solutions derived for the whole parameter domains based on data for a globally representative individual suggest that whenever environmental sustainability is pursued for welfare reasons within a utilitarian perspective (i.e., WS, AG, DG), it is not worth pursuing. In contrast, if environmental sustainability is achieved for ethical reasons within an egalitarian perspective (i.e., SS), it is worth pursuing, even with an increased world population. In terms of feasibility (i.e., whether there are realistic parameter values such that a given sustainability paradigm can achieve its goal), solutions are ranked ethics $>$ preference $>$ technology (i.e., SS $>D G>A G$ ), whereas WS is unfeasible. Thus, WS, AG, and DG are inconsistent sustainability paradigms, SS empirically solves the theoretical dispute on absolute rights, and environmental sustainability must be treated as an ethical issue. A conceptual discussion about environmental ethics and a statistical analysis based on panel data at a country level support the same insights. In terms of reliability (i.e., whether there are national policies or international agreements which can support a feasible sustainability paradigm), SS could be enforced by a global environmental agreement, supported by $66 / 55 \%$ of governments (i.e., top-down approach) and by $56 / 51 \%$ of citizens (i.e., bottom-up approach), in the most certain/uncertain scenarios, respectively.
\end{abstract}

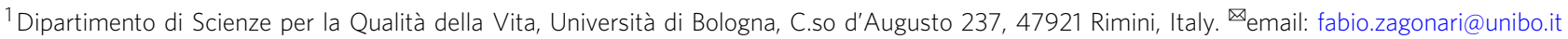




\section{Introduction}

- he literature has recently begun to discuss to what extent global environmental sustainability is a technology issue or a preference issue (Bezin, 2019; Santarius and Soland, 2018; Tran, 2016; Aznar-Marquez and Ruiz-Tamarit, 2016; Zagonari, 2015). In particular, Zagonari (2015) empirically demonstrated that individuals in better-off developed countries and individuals in worse-off developing countries can achieve sustainability with a reasonable level of value changes (0 to $30 \%$ decrease in the preference for consumption) and a feasible degree of technological innovation (10 to $40 \%$ increase in efficiency), respectively, whereas individuals in better-off developing countries and individuals in worse-off developed countries must rely on an impractical degree of technological innovation (50 to 70\% increase) and on an unreasonable level of value changes (40 to $70 \%$ decrease), respectively.

The literature has also recently begun to emphasize the role of ethics in achieving global environmental sustainability (Menning, 2016; Lenzi, 2017; Spahn, 2018). In this context, two main groups of environmental ethics can be identified: secular and religious ethics. Secular ethics focus on our perceived responsibility to nature, perceived responsibility to future generations, perceptions of the relative rights of humans and non-humans, and beliefs in inter-generational and intra-generational equity (Zagonari, 2018). In contrast, religious ethics have a different primary focus in each religion: Judaism focuses on stewardship (here, maximizing the use of resources to achieve the highest sustainable total welfare), Islam focuses on trusteeship and parsimony (here, minimizing the use of resources), Hinduism and Buddhism focus on maintaining equilibrium, and Christianity focuses on love of neighbors (Zagonari, 2020). In particular, Zagonari (2019a) empirically shows that the perception of a sense of duty to nature is a beneficial but unfeasible and unreliable way to achieve sustainability in developed countries; in contrast, the perception of a duty to future generations is detrimental to sustainability in both developed and developing countries; belief in the rights of future generations is a beneficial and reliable but unfeasible way to achieve sustainability in developed countries; intra-generational inequality is detrimental, and inter-generational inequality is essential, to achieving sustainability in both developed and developing countries; in contrast, all secular ethics are unfeasible and unreliable in developing countries. The religious ethics were adequate, feasible, and reliable for Hinduism or Buddhism, Islam, and Judaism, but were unfeasible for Christianity.

However, these papers did not account for uncertainty in the preferences for consumption that characterize future generations and in the technologies that may be available to future generations. Indeed, the current generation is expected to bear certain monetary or opportunity costs to promote environmental sustainability despite uncertainty about the perceived benefits for future generations (e.g., think of ecosystem services) and the costs they must bear (e.g., think of innovation expenditures). In other words, the inter-generational discount rate applied to welfare could be larger than its minimum (i.e., 0 ) or the aversion to intergenerational inequality could be smaller than its maximum (i.e., 1) if future generations can rely on technologies or are characterized by preferences that imply a smaller use of resources.

Four main sustainability paradigms have been suggested: weak sustainability (WS), a-growth (AG), de-growth (DG), and strong sustainability (SS). WS is defined as the maximization of current and future generations' welfare subject to the constraint that future generations' welfare must be at least equal to that of current generations (Schlör et al., 2015). AG is defined as the maximization of current and future generations' welfare subject to the constraint of sustainable use of resources permitted by technological innovations (Van den Bergh, 2010, 2011). DG is defined as a sustainable use of resources subject to the constraint that future generations' welfare must be at least equal to current generations' welfare due to preference changes (Kallis, 2011; Kallis et al., 2012). SS is defined as a sustainable use of resources subject to inter-generational equity in resource use (Jain and Jain, 2013).

The purpose of this paper is to test which sustainability paradigm is worth pursuing, with worth determined by comparing the benefits and costs, once uncertainties about future preferences and technologies have been taken into account. Indeed, WS, AG, and DG are based on a utilitarian perspective, whereas SS is based on an egalitarian perspective. AG depends on technological innovations that future generations can adopt, whereas DG relies on preference changes that current generations should espouse. SS rests on the intrinsic value of equality in the distribution of resources between current and future generations. In other words, by relying on the different features that characterize the four sustainability paradigms, I will test whether sustainability depends most strongly on technology (i.e., AG), consumption preferences (i.e., DG), or ethics (SS).

Note that I will focus on a globally representative individual (i.e., sustainability includes the whole world's population). However, I will also discuss (Supplementary Appendix II) the distribution among countries of the costs that must be paid to achieve sustainability (i.e., both OECD and non-OECD pre-industrial, industrial, postindustrial countries). Moreover, I have chosen WS as the reference sustainability paradigm against which the other forms will be compared within a utilitarian perspective without requiring changes in technology and preferences. Finally, I will focus on feasibility, which I define as whether there are realistic parameter values for future technologies and preferences such that a given sustainability paradigm can achieve a satisfactory level of effectiveness, if properly implemented. However, I will also provide insights (Supplementary Appendix III) into reliability, which I define as whether there are environmental national policies or international agreements which can enforce a feasible sustainability paradigm, based on a theoretical discussion and an empirical analysis.

\section{Methods}

Zagonari (2018) highlighted the main features of the four sustainability paradigms. Supplementary Appendix I characterizes the main features of these four sustainability paradigms within the main approaches to environmental ethics about non-humans and future generations. Here, I will use the constraints of these four sustainability paradigms by comparing them in terms of the set of parameters that meet the conditions for a feasible solution after accounting for uncertainty in future technologies and preferences. In particular, I will assume that the current generation is concerned about future generations, and I will focus on only two generations; the current and next generations. This can be justified by the evidence that the current generation perceives more accurately the near future (i.e., within their lifetime and that of their immediate descendants) than the distant future (Diprose et al., 2019), together with the urgency of the global sustainability problem (Rockstrom et al., 2017). Moreover, I will assume a normal distribution for future consumption preferences $p(\eta)$ and technologies $p(\theta)$, with alternative variances $(\sigma)$ representing uncertainty, but with means $(\mu)$ at 1.0 and 0.5 , respectively. That is, the most likely future preferences are current preferences, whereas the most likely future technologies are twice as efficient as current technologies. This choice of values for the means is supported by the observed world dynamics of two variables in the World Bank's world development indicators database (http:// data.worldbank.org). In particular, energy use divided by per capita GDP on a purchasing power parity (PPP) basis amounted 


\section{Table 1 Summary of the notation and parameter values.}

\section{Definition}

Proportion of per capita GDP allocated to consumption

Proportion of per capita GDP allocated to nature conservation

Proportion of per capita GDP allocated to green R\&D

Aversion to inter-generational inequality

Ratio of current preference for consumption to future preference

Ratio of the efficiency of current technologies to future technologies

Current GDP per unit use of resources

Current per capita resource use in terms of ecological footprint

Sustainable per capita resource use in terms of ecological footprint

Probability of observing a given $\eta$ for future preferences

Probability of observing a given $\theta$ for future technologies

Mean of $\eta$ or $\theta$ for future technology or preferences

Variance of $\eta$ or $\theta$ for future technology or preference

Welfare of current generation

Welfare of future generation

\section{Value}

$58 \%$

$2 \%$

$1 \%$

$[0,1]$, where 1 is the maximum

$[0.5,1.5]$, where 0.5 is the worst

$[0,1]$, where 0 is the best

$4.78 \mathrm{USD} / \mathrm{ha}$

2.79 ha

1.70 ha

$\mathrm{N}[\mu, \sigma]$ or Uniform distribution

$\mathrm{N}[\mu, \sigma]$ or Uniform distribution

1 for $\eta$ and 0.5 for $\theta$

$1,2,3,4$

4.38

3.37

Each value not assumed in a specified range is based on the World Bank's world development indicators database in 2012.

to $0.29 \mathrm{~kg}$ of oil equivalent in 1990 and 0.12 in 2014 , with an average (linear) decrease per year of 0.007 and an overall decrease of $58 \%$ during this period; in addition, the share of household consumption expenditure based on per capita GDP was $59.0 \%$ in 1970 and $57.9 \%$ in 2017 , with an average (linear) decrease per year of 0.002 and an overall decrease of $1 \%$ during this period. Note that I will perform sensitivity analyses that assume uniform distributions for future preferences and technologies (i.e., the probability of all possible values for future preferences and technologies is the same). Finally, current costs are represented by a possible reduction in current consumption, whereas future gains are depicted by a sustainable society. This is justified by the assumptions that humanity's purpose is to continue to exist (i.e., based on the direct deontological value of the future generation) and to alleviate pain (i.e., based on the indirect teleological value of the next generation) (Franco et al., 2019).

Table 1 summarizes the notation I will use in the rest of this Section and the values I used in Results. Note that it is implicitly assumed that the current generation is risk neutral (i.e., it refers to expected value), sustainability is properly measured by the ecological footprint, and the next generation has the same size as the current generation (i.e., the sustainable per capita resource use in terms of ecological footprint is based on the current population).

Note that I will not consider the perceived duty to the current generation ( $\delta$ in Zagonari, 2018), which represents the concern of citizens in developed countries for citizens in developing countries. This is because my analysis focuses on a globally representative individual. Future research could add this factor to the analysis. Moreover, my focus on only two generations (i.e., a period of ca. 25 years) is consistent with the urgency of the global sustainability problem (www.sdgindex.org/reports/2018). Finally, I will not consider intra-generational equity ( $\varepsilon$ in Zagonari, 2018), since my focus is on a globally representative individual. Future research could add this factor to the analysis.

In the simplified context described above, WS can be depicted as follows:

$$
U_{\mathrm{F}}=\left(\lambda E_{\mathrm{S}}\right)^{\alpha} \geq U_{\mathrm{C}}=\left\{\left[(\lambda E)^{\alpha} E^{-\beta} U_{F}^{\gamma}\right]^{1 /(1-\zeta)}+U_{\mathrm{F}}^{1 /(1-\zeta)}\right\}^{1-\zeta}
$$

However, future technologies and consumption preferences are uncertain. Thus, it is worthwhile pursuing WS (i.e., the undiscounted benefits are larger than the costs) if the following condition holds:

$$
\begin{aligned}
U_{\mathrm{F}} \geq & \left\{\left[(\lambda E)^{\alpha} E^{-\beta} U_{\mathrm{F}}{ }^{\gamma}\right]^{1 /(1-\zeta)}+U_{\mathrm{F}}{ }^{1 /(1-\zeta)}\right\}^{1-\zeta}- \\
& \left\{\left[\left(\lambda E_{\mathrm{S}}\right)^{\alpha} E_{\mathrm{S}}{ }^{-\beta} U_{\mathrm{F}}{ }^{\gamma}\right]^{1 /(1-\zeta)}+U_{\mathrm{F}}{ }^{1 /(1-\zeta)}\right\}^{1-\zeta}
\end{aligned}
$$

where

$$
U_{\mathrm{F}}=\left(\frac{\lambda}{\theta} p(\theta) E_{\mathrm{S}}\right)^{\alpha \eta p(\eta)}
$$

With $\theta$ in $[0,1]$ to depict the current technology (i.e., $\theta=1$ ) and the infinitely more efficient future technology (i.e., $\theta=0$ ), and $\eta$ in $[0.5,1.5]$ to depict the current preference (i.e., $\eta=1$ ) and the more or less demanding future preference (i.e., $\eta=0.5$ or $\eta=1.5$, respectively).

In the simplified context described above, AG can be depicted as follows:

$U_{\mathrm{F}}=\left(\lambda_{\mathrm{AG}} E_{\mathrm{S}}\right)^{\alpha} \geq U_{\mathrm{C}}=\left\{\left[\left(\lambda E_{\mathrm{S}}\right)^{\alpha} E_{\mathrm{S}}{ }^{-\beta} U_{\mathrm{F}}{ }^{\gamma}\right]^{1 /(1-\zeta)}+U_{\mathrm{F}}{ }^{1 /(1-\zeta)}\right\}^{1-\zeta}$

With

$$
\lambda_{\mathrm{AG}}=(\lambda E) / E_{\mathrm{S}}>1
$$

In words, the current generation bears the costs of the transition to more efficient technologies (i.e., $\lambda_{\mathrm{AG}}>\lambda$ ) by paying larger prices for the same consumption level (i.e., $\lambda_{\mathrm{AG}} E_{\mathrm{S}}=\lambda E$ ). However, future technologies and preferences are uncertain. Thus, it is worthwhile pursuing AG (i.e., the undiscounted benefits are larger than the costs) if the following condition holds:

$$
\begin{gathered}
U_{\mathrm{F}} \geq\left\{\left[(\lambda E)^{\alpha} E^{-\beta} U_{\mathrm{F}}{ }^{\gamma}\right]^{1 /(1-\zeta)}+U_{\mathrm{F}}{ }^{1 /(1-\zeta)}\right\}^{1-\zeta}- \\
\left\{\left[\left(\lambda E_{\mathrm{S}}\right)^{\alpha} E_{\mathrm{S}}{ }^{-\beta} U_{\mathrm{F}}{ }^{\gamma}\right]^{1 /(1-\zeta)}+U_{\mathrm{F}}{ }^{1 /(1-\zeta)}\right\}^{1-\zeta}
\end{gathered}
$$

where

$$
U_{\mathrm{F}}=\left(\frac{\lambda_{\mathrm{AG}}}{\theta} p(\theta) E_{\mathrm{S}}\right)^{\alpha \eta p(\eta)}
$$


In the simplified context described above, DG can be depicted as follows:

$$
U_{\mathrm{F}}=\left(\lambda E_{\mathrm{S}}\right)^{\alpha \mathrm{DG}} \geq U_{\mathrm{C}}=\left\{\left[\left(\lambda E_{\mathrm{S}}\right)^{\alpha \mathrm{DG}} E_{\mathrm{S}}{ }^{-\beta} U_{\mathrm{F}}{ }^{\gamma}\right]^{1 /(1-\zeta)}+U_{\mathrm{F}}{ }^{1 /(1-\zeta)}\right\}^{1-\zeta}
$$

With

$$
\alpha_{\mathrm{DG}}=\alpha\left(\log [\lambda E] / \log \left[\lambda E_{\mathrm{S}}\right]\right)
$$

In words, the current generation attaches a greater value to the current consumption level (i.e., $\alpha_{\mathrm{DG}}>\alpha$ ) to achieve the same welfare at a sustainable consumption level (i.e., $(\lambda E)^{\alpha}=\left(\lambda E_{\mathrm{S}}\right)^{\alpha \mathrm{DG}}$ ). However, future technologies and consumption preferences are uncertain. Thus, it is worthwhile pursuing DG (i.e., the undiscounted benefits are larger than the costs) if the following condition holds:

$$
\begin{gathered}
U_{\mathrm{F}} \geq\left\{\left[(\lambda E)^{\alpha} E^{-\beta} U_{\mathrm{F}}^{\gamma}\right]^{1 /(1-\zeta)}+U_{\mathrm{F}}^{1 /(1-\zeta)}\right\}^{1-\zeta}- \\
\left\{\left[\left(\lambda E_{\mathrm{S}}\right)^{\alpha \mathrm{DG}} E_{\mathrm{S}}{ }^{-\beta} U_{\mathrm{F}}{ }^{\gamma}\right]^{1 /(1-\zeta)}+U_{\mathrm{F}}{ }^{1 /(1-\zeta)}\right\}^{1-\zeta}
\end{gathered}
$$

where

$$
U_{\mathrm{F}}=\left(\frac{\lambda}{\theta} p(\theta) E_{\mathrm{S}}\right)^{\alpha \mathrm{DG} \eta p(\eta)}
$$

In the simplified context described above, SS can be depicted as follows:

$$
E=E_{\mathrm{s}}
$$

Thus, it is worth pursuing SS (i.e., the undiscounted benefits are larger than the costs) if the following condition holds:

$$
U_{\mathrm{F}} \geq(\lambda E)^{\alpha} E^{-\beta} U_{\mathrm{F}}^{\gamma}-\left(\lambda E_{\mathrm{S}}\right)^{\alpha} E_{\mathrm{S}}{ }^{-\beta} U_{\mathrm{F}}^{\gamma}
$$

where

$$
U_{\mathrm{F}}=\left(\frac{\lambda}{\theta} p(\theta) E_{\mathrm{S}}\right)^{\alpha \eta p(\eta)}
$$

Note that the competitive general equilibrium framework amounts to WS without constraints or with non-binding constraints (i.e., sustainability within a competitive general equilibrium framework is easier to achieve than WS due to the possible substitution between current and future welfare). Moreover, a discount factor of 0 amounts to an inter-generational inequality aversion of 1, although the former should be correctly applied to welfare, whereas the latter can be properly applied to resources. Finally, SS is equivalent to an eco-centric Deep Ecology framework for each time $t$ and for each species (i.e., sustainability within an eco-centric Deep Ecology framework is easier to achieve than SS due to its references to resilience or resistance goals and, consequently, its larger flexibility of equilibria).

Table 2 summarizes the main features of the four sustainability paradigms.

Note that the substitutability of natural capital with other forms of capital, which is allowed in all paradigms except SS, is depicted by using welfare for WS, AG, and DG, but by using resources for SS. Moreover, I assumed a constant population (i.e., the sustainable per capita use of resources is the same for the current and next generations). Finally, the benefits and costs for WS with substitutability equals the benefits and costs for SS without substitutability (i.e., with $U_{\mathrm{F}} \geq U_{\mathrm{C}}$ instead of $E_{\mathrm{F}} \geq E_{\mathrm{C}}$ ) if the maximum aversion to inter-generational inequality applies (i.e., with $\zeta=1$ instead of $\zeta<1$ ).

From the World Bank's world development indicators database (http://data.worldbank.org), I obtained the proportion of per
Table 2 Comparison of the four environmental sustainability paradigms (WS weak sustainability, AG, a-growth, DG degrowth, SS strong sustainability).

\begin{tabular}{lllll} 
& Conditions & Technologies & Preferences & $\begin{array}{l}\text { Intergenerational } \\
\text { inequity aversion }\end{array}$ \\
\hline WS & $U_{F} \geq U_{C}$ & $\lambda$ & $\alpha$ & $\zeta<1$ \\
AG & $U_{F} \geq U_{C}$ & $\lambda_{A G}$ & $\alpha$ & $\zeta<1$ \\
$D G$ & $U_{F} \geq U_{C}$ & $\lambda$ & $\alpha_{D G}$ & $\zeta<1$ \\
SS & $E_{F} \geq E_{C}$ & $\lambda$ & $\alpha$ & $\zeta=1$ \\
\hline Variables: $U_{F}$, future utility; $U_{C}$, current utility; $E_{F}$, future ecological footprint; $E_{C}$, current \\
ecological footprint; $\lambda$, use of resources per unit GDP; $\alpha$, proportion of per capita GDP allocated \\
to consumption; $\zeta$, aversion to inter-generational equity.
\end{tabular}

capita GDP allocated to consumption (PPP) in 2012 ( $\alpha$ ): 58\%. I based the concern about the use of the environment (expressed in terms of the investment in conservation of natural resources, $\beta$ ) on the observed average government expenditure on environmental protection as a percentage of GDP in OECD countries (i.e., 1.7\%; http://www.oecd-ilibrary.org). For concreteness, the proportion of per capita GDP allocated to nature conservation is rounded below at $\beta=0.01$ for the world. I based the current generation's concern for the future generation $(\gamma)$ on the average observed expenditure on environmental $\mathrm{R} \& \mathrm{D}$ and patents as a percentage of GDP observed in OECD countries (i.e., 2.4\%; http://www.oecd-ilibrary.org). For concreteness, the proportion of per capita GDP allocated to environmental R\&D and patents is rounded below at $\gamma=0.02$ for the world. From the World Bank's world development indicators (http://data.worldbank.org), I obtained the global per capita GDP (PPP) in 2012: USD 13 348. If the per capita use of the global environment is measured by the ecological footprint (i.e., the biologically productive area needed to provide everything an individual consumes), the sustainability of a globally representative individual at the current population level requires $E_{\mathrm{S}}=1.70$ ha (http://www.footprintnetwork.org), whereas the use of the environment, based on data for 2012, is $E=2.79$ ha. Thus, the per capita use of the global environment for GDP PPP $(\lambda)$ is set at $4.78 \mathrm{USD} /$ ha (i.e., USD 13348 divided by $2.79 \mathrm{ha})$. These parameters imply that $U_{\mathrm{C}}=4.38$ and $U_{\mathrm{F}}=3.37$. Moreover, $p(\eta)$ can be represented by $\mathrm{N}[1, \sigma]$ with $\sigma=1,2,3$, and 4 , by assuming that the current value of $\alpha$ is the most likely value in the future. This is supported by data at a global level (http://data.worldbank.org), which implies that $p$ $(\eta=1.5)$ is $0.35,0.19,0.13$, and 0.09 for $\sigma=1,2,3$, and 4 , respectively. Finally, $p(\theta)$ can be represented by $\mathrm{N}[0.5, \sigma]$ with $\sigma=1,2,3$, and 4 , by assuming that half of the current value of $\lambda$ is the most likely value in the future. This is supported by data at a global level (http://data.worldbank.org), which implies that $p$ $(\theta=0)$ is $0.35,0.19,0.13$ and 0.09 for $\sigma=1,2,3$, and 4 , respectively.

\section{Results}

In this section, I will present the sets of $\eta$ and $\theta$ which satisfy the conditions defined in Methods for the four sustainability paradigms in the main scenario (i.e., normal distributions for both future preferences and future technologies) for the world representative individual in 2012 with a constant world population. Here, I define an "equivalence curve" as the couples of $\eta$ and $\theta$ such that the benefits equal the costs.

Supplementary Materials present sensitivity analyses based on an increased world population (i.e., 10 billion, according to the World Bank projection to 2050), on the one side, and, on the other side, based on uniform distributions of preferences (i.e., future preferences depicted by $\eta$ will be observed without 
uncertainty), uniform distributions of technologies (i.e., future technologies depicted by $\theta$ will be observed without uncertainty), and uniform distributions of both preferences and technologies (i.e., future preferences and technologies depicted by $\eta$ and $\theta$, respectively, will be observed without uncertainty).

Supplementary Appendix II presents probit estimations based on a panel dataset for 181 countries from 1995 to 2017 to check whether feasibility conditions (i.e., inequalities $1,3,5,7$ ) and worthiness conditions (i.e., inequalities $2,3,6,8$ ) are satisfied at country level, by focusing on specified groups of countries (i.e., pre-industrial, industrial OECD and non-OECD, post-industrial OECD and non-OECD). Supplementary Appendix III characterizes the main features of the collective action problems involved in enforcing the egalitarian ethics behind the SS paradigm, by presenting national policies and international agreements within consequentialist and deontologist approaches.

Note that the world-representative individual approach (adopted in this section) is grounded on sustainability being a global issue, whereas the country-representative individual approach (adopted in Supplementary Appendixes II and III) is founded on environmental policies and agreements being implemented and negotiated at a country level. The first approach compares ethics, preferences and technologies in terms of feasibility, with implications for sustainability paradigms to be pursued; the second approach highlights which country is more likely to benefit from pursuing global sustainability, with implications for international negotiations. In particular, the original panel dataset at a country level accounts for both individual feelings and social identity (i.e., the main determinants of pro-environmental behaviors) (Zagonari, 2018). Moreover, the theoretical conditions required to apply the representative individual at a country level are satisfied (Zagonari, 2019b). Finally, the original panel dataset for observed (rather than self-stated) pro-environmental behaviors avoids the intention-action and attitude-action gaps (Zagonari, 2020).

Figure 1 shows all possible combinations of $\eta$ and $\theta$ that meet the conditions for WS and AG with $\sigma$ at 1, 2, 3, and 4. For WS, there are no solutions for any value of $\sigma$. For AG, there are no solutions for $\sigma=2,3$, and 4 (i.e., large values of $\sigma$ imply more demanding changes in technologies and preferences), whereas if $\sigma=1$, an unrealistic solution could be achieved if the future generation attaches $50 \%$ more value to consumption than the current generation (i.e., they obtain $150 \%$ of current satisfaction from the same current consumption level) and if the future generation can rely on a technology that is $98 \%$ more efficient (i.e., they obtain the same consumption level by using $2 \%$ of the current resources).

Figure 2 shows all possible combinations of $\eta$ and $\theta$ that provide sustainability for DG and SS with $\sigma$ at 1, 2, 3, and 4. For DG, if $\sigma=3$ or 4, there are no solutions (i.e., large values of $\sigma$ imply more demanding changes in technologies and preferences), whereas if $\sigma=1$ or 2, an unrealistic solution could be achieved if the current generation attaches $50 \%$ more value to consumption (i.e., they obtain $150 \%$ satisfaction from the same current consumption level) and if the future generation can rely on a technology that is $97 \%$ more efficient than the current technology (i.e., they obtain the same consumption level by using $3 \%$ of the current resources). For SS, there is a solution for all values of $\eta$ and $\theta$ in the domains if $\sigma=2,3$ and 4, whereas if $\sigma=1$, a realistic solution could be achieved if the future generation attaches the same value to consumption (i.e., they obtain the same satisfaction from the current consumption level), and if the future generation can rely on a technology that is $5 \%$ more efficient than the current technology (i.e., they obtain the same consumption level by using $95 \%$ of the current resources).

In summary, WS is never feasible. AG is feasible in 1 out of 4 scenarios (i.e., the most certain condition with $\sigma=1$ ), but with

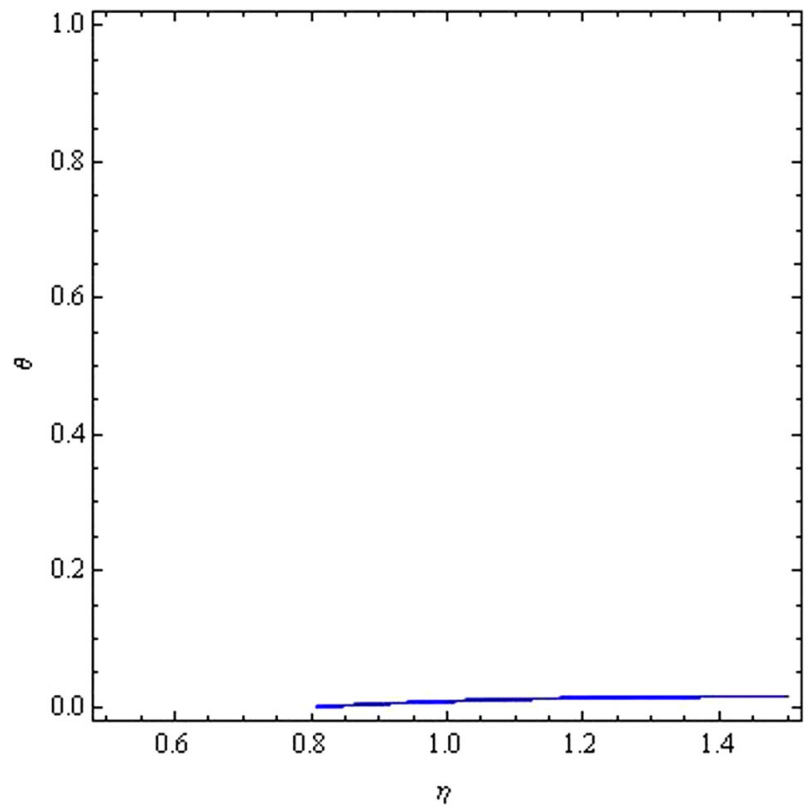

Fig. 1 Feasible solutions (areas below the equivalence curves) if the weak sustainability (WS) and a-growth (AG) paradigms are applied for combinations of future technologies $(\theta)$ and preferences $(\eta)$, where $\theta=1$ depicts current technology and $\boldsymbol{\eta}=\mathbf{1}$ depicts the current preference for consumption. WS (yellow) is never feasible, so it is not shown. For AG (blue), the only feasible equivalence curve refers to $\sigma=1$ (the most certain scenario); there are no feasible equivalence curves for $\sigma=2,3$, and 4 .

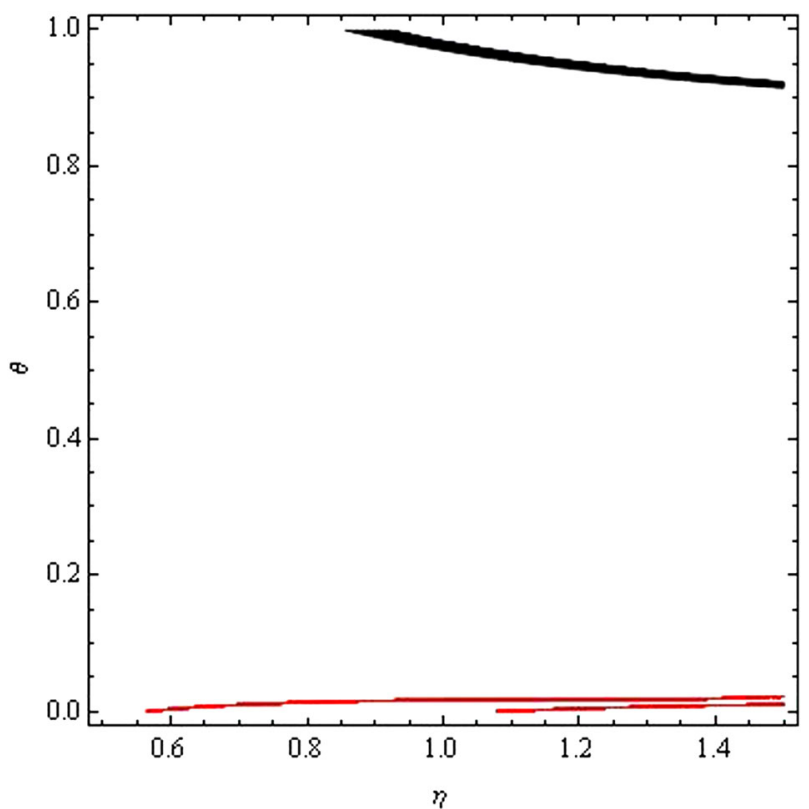

Fig. 2 Feasible solutions (areas below the equivalence curves) if the degrowth (DG) and strong sustainability (SS) paradigms are applied for combinations of future technologies $(\theta)$ and preferences $(\eta)$, where $\theta=1$ depicts current technology and $\boldsymbol{\eta}=1$ depicts the current preference for consumption. For DG (red), the higher equivalence curve refers to $\sigma=1$ (i.e., the most certain scenario), the lower equivalence curve refers to $\sigma=2$, and there are no equivalence curves for $\sigma=3$ and 4 . For SS (black), the single equivalence curve refers to $\sigma=4$ (i.e., the most pessimistic scenario), but feasibility conditions are met for $\sigma=1,2$, and 3 . 
unrealistic changes in future technologies (i.e., $98 \%$ more efficient as depicted by $\theta=0.02$ ): a larger value must be attached to consumption for less efficient technologies (i.e., the equivalence curve for $\theta$ is increasing with increasing $\eta$ ). DG is feasible in 2 out of 4 scenarios (i.e., the most certain conditions with $\sigma=1$ or 2 ), but with unrealistic changes in future technologies (i.e., $97 \%$ more efficient as depicted by $\theta=0.03$ ): a larger value must be attached to consumption for less efficient technologies (i.e., the equivalence curve for $\theta$ is increasing with increasing $\eta$ ). SS is feasible in all scenarios, although in the most pessimistic scenario, small changes in future technologies (i.e., from 0 to $8 \%$ more efficient as depicted by $\theta=0.92$ ) or future preferences (i.e., from 0 to $50 \%$ more demanding as depicted by $\eta=1.5$ ) are required: a smaller value must be attached to consumption for less efficient technologies (i.e., the equivalence curve for $\theta$ is decreasing with increasing $\eta$ ).

Figures S1 and S2 in Supplementary Materials account for the estimated increase in the world population, by considering a smaller per capita amount of resources in equilibrium. In short, unfeasibility of WS, AD, and DG is unaffected, whereas SS is still feasible in the most certain scenario for realistic changes in future technologies and preferences.

Figures S3 to S7 in Supplementary Materials examine the consequences of the assumption of uniform distributions of future preferences, technologies or both. In short, eliminating uncertainty about future technology levels has a smaller impact on feasibility than eliminating uncertainty about future preferences.

\section{Discussion}

There is no literature on the effects of uncertainty in future technologies and preferences on alternative sustainability paradigms within an empirically validated theoretical framework for religious or secular environmental ethics. Thus, it is not possible to compare insights obtained in this paper with results achieved by other studies.

Nevertheless, the main weaknesses of this study are as follows:

- I only consider one ethical principle (i.e., inter-generational egalitarianism), with the maximum value for SS, and values smaller than the maximum for WS, AG, and DG. This ignores other ethical principles, such as secular ethics related to anthropocentric vs. biocentric values, duties to nature or the future generation vs. rights of nature or the future generation, direct vs. indirect duties, and utilitarian vs. egalitarian perspectives (See Supplementary Appendix I for a comprehensive summary of environmental ethics). For religious ethics, it ignores primary focuses such as stewardship in Judaism, trusteeship and parsimony in Islam, maintaining equilibrium in Hinduism and Buddhism, and love of neighbors in Christianity. However, future research could refer to other ethical principles and religious precepts depicted by quantity variables within a mathematical framework (e.g., Zagonari, 2018; Zagonari, 2020).

- The focus is only on global and systemic sustainability, and ignores local and sectoral sustainability. However, future research could test if environmental services that require ethical improvements (e.g., for local soil sustainability, waste separation to increase recycling, including composting; for local water sustainability, purchasing organic food to decrease water pollution by reducing the use of pesticides and fertilizers in agriculture; for global air sustainability, conserving energy by updating a home's heating or air conditioning systems and light bulbs and by changing some lifestyle choices such as dressing warmer to reduce the need for heating or switching off lights in empty rooms to reduce energy consumption and to decrease greenhouse gas emissions) can be promoted by religious or secular ethics.

- I consider both feasibility and reliability of the only feasible sustainability paradigm (i.e., SS), by empirically calculating the proportions of governments (i.e., top-down approach) and citizens (i.e., bottom-up approach) which would vote in favor of a (balanced, stable, and efficient) global environmental agreement designed to implement SS (see Supplementary Appendix III for an ample discussion of national policies and international agreements to cope with the collective action problems involved in enforcing the egalitarian ethics behind SS). However, future research could apply inter-disciplinary approaches to check for the existence of strong relationships between pro-environmental behaviors and religious or secular ethics (e.g., Zagonari (2020) on religious precepts), as well as for the existence of strong relationships between pro-environmental behaviors and international agreements (e.g., Mauerhofer (2019) on the operating rules of environmental secretariats; Iyer et al. (2018) on comparability of national contribution to sustainable development to avoid free-riding; Chen et al. (2018) on selfenforcing international environmental agreements; Shutters (2016) on incentives and/or deterrents to restructure national strategies to achieve sustainability at a global scale; Kim and Bosselmann (2015) on ecological principles for international law).

Note that my focus is on a globally representative individual so the scale of value provider is disregarded; my use of instrumental rationality within a normative perspective neglects communicative and bounded rationality, as well as recognition and procedural justice; and my focus is on ethics as transcendental values so contextual values are disregarded (Kenter et al., 2019)

In contrast, the main strengths of this study are as follows:

- It adopts a quantitative rather than a qualitative approach by developing a theoretical model based on measurable variables that let me find empirically calibrated solutions.

- The analysis is performed at a global and a country level rather than at an individual level. The global theoretical model let me eliminate the gap between an individual's expressed belief and their actions, to elicit persistent rather than situational influences on behavior, and to minimize the gap between reality and the simulation (Basedau et al., 2018).

- The paper considers ethics as a policy rather than as personal traits, learning styles, values, and attitudes. The theoretical model therefore let me include ethics to compare its collective effects on promoting pro-environmental behaviors to achieve global sustainability in terms of their feasibility.

Note that my finding that SS $>$ DG $>$ AG in terms of feasibility is consistent with the change in preferences required by DG being similar to ethics, since this change in the value attached to consumption is based on a perceived duty to nature. Moreover, SS empirically solves the theoretical dispute on absolute rights of future generations (Skillington, 2019), since it theoretically assumes (ex-ante) that inter-generational equity is pursued regardless of its costs, but it turns out (ex-post) that benefits are larger than costs. Finally, SS is a sustainability paradigm, whereas Deep Ecology is an environmental framework, since it also considers social issues (i.e., economic issues are instrumental to social issues) by referring to the per capita amount of resources. Although SS is focused on future generations (i.e., pain alleviation of the current generation is less important than human continuity for SS with respect to the main religions), the social issue could be accounted for by considering the per capita minimum amount of resources and the intra-generational distribution of resources for the current generation. 
Combining Tables 3 and 4 in Supplementary Appendix I, under the assumption that ethical rules have no intrinsic values (i.e., ethical rules are instrumental to achieve environmental sustainability), leads to the conclusion that environmental ethics should refer to ethical principles behind the strong sustainability paradigm (based on the intrinsic value of future generations), the eco-centric framework (based on the intrinsic value of nature) or the ethical precepts behind the main religions. Indeed, rights of future generations or non-humans (i.e., limits to interests or actions of current generation to enforce interests or actions of future generations or non-humans) cannot be tightly supported by laws, although somebody complains and restoration is possible (Riley, 2016). In other words, exclude last columns on rights in Tables 3 and 4 . Uncertainty on future technologies or preferences leads to disregard ethics based on welfare or eudemonic outcomes (results highlighted above; Schaffartzik et al., 2016). In other words, exclude columns on teleological approaches in Tables 3 and 4. Urgency of environmental sustainability implies that indirect duties to nature is inadequate (Steffen et al., 2015). In other words, exclude columns on duties to next generation in Table 4 . Note that SS persists both in Table 3 and in Table 4.

In summary, although this paper focuses on inter-generational commutative egalitarianism behind SS as the only (secular) ethical principle to achieve environmental sustainability, within the world-representative individual approach, SS turns out to be the only consistent (social and environmental) sustainability paradigm (i.e., eco-centric and biomimetic are a-social and antisocial ethics, respectively). Note that Zagonari (2019a) empirically supports this conclusion, by comparing secular and religious environmental ethics.

Table 14 in Supplementary Appendix II confirms at country level the ranking of worthiness across sustainability paradigms obtained for the world-representative individual: SS > DG, where DG is feasible in the most certain scenario only; AG and WS are unfeasible in all scenarios. Note that this is a remarkable result, since the decision to adopt a sustainability paradigm in order to achieve global sustainability for the world-representative individual might be different from the majority decision of 181 countryrepresentative individuals, which depends on the country resource uses and welfare levels. In particular, the ranking of worthiness for SS across countries based on the comparisons between benefits (i.e., a sustainable future generation) and costs (i.e., a renounce to current welfare) is as follows: pre-industrial countries are most likely to benefit from adopting SS for ethical reasons (i.e., they renounce to current welfare as a small cost); then industrial countries (i.e., they achieve sustainability as a large future benefit); then post-industrial OECD countries (i.e., they achieve sustainability as a large future benefit by renouncing to current welfare as a large cost); then industrial OECD countries (i.e., they achieve sustainability at a larger relative cost than industrial non-OECD countries); and then post-industrial non-OECD countries (i.e., they achieve sustainability at a larger relative cost than postindustrial OECD countries). Moreover, an increase in uncertainty about future preferences and technologies reduces the worthiness probabilities for all groups of countries. Finally, effectiveness of environmental policies reduces the worthiness difference between different sustainability paradigms (i.e., worthiness probabilities for SS and DG are closer in OECD countries than in non-OECD countries). Note that the most likely worthiness probability of preindustrial and industrial non-OECD countries is a beneficial result for the world, since they represent $70 \%$ of the global population. However, it might be a detrimental result for these countries, since they are likely to have a smaller bargaining power in international negotiations about environmental agreements.

In summary, within the country-representative individual approach, WS and AG turn out to be unfeasible sustainability paradigms, DG is feasible in the most certain scenario for all groups of countries apart from post-industrial non-OECD countries, and SS is feasible (i.e., environmental sustainability is pursued for ethical reasons) and worth (i.e., benefits are larger than costs) for all groups of countries in all scenarios, although worthiness probability is different across countries and scenarios.

Table 16 in Supplementary Appendix III shows the proportions of governments and citizens which would vote in favor of a global environmental agreement designed to implement the SS paradigm. These proportions are smaller with a larger uncertainty (to the largest extent if $\sigma=1$ is replaced with $\sigma=2$ ), and they are larger for longer commitments (to a greater extent for governments than for citizens).

In summary, a global environmental agreement which solves the collective action problems involved in the egalitarian ethics behind the SS paradigm seem to be reliable, although a top-down should be preferred to a bottom-up approach, and a longer should be preferred to a shorter commitment.

\section{Conclusion}

By comparing the costs and benefits of different (secular) sustainability paradigms, this paper revealed that whenever environmental sustainability is pursued for welfare reasons within a utilitarian perspective (i.e., WS, AG, DG), it is not worth pursuing because the benefits do not exceed the costs. In contrast, if environmental sustainability is achieved for ethical reasons within an egalitarian perspective (i.e., SS), it is worth pursuing because the benefits do exceed the costs. In other words, environmental sustainability is best considered as a (secular or religious) ethical issue (White, 1967), and SS is the only (secular) consistent sustainability paradigm.

However, SS is difficult to implement, since it relies on intergenerational equity. Consequently, scholars should focus on specific principles from secular ethics or specific precepts from religious ethics that favor the achievement of the global sustainability discussed in this paper or alternative combinations of global plus local or systemic plus sectoral sustainability. In particular, SS is a complicated collective action problem, since there are few governmental rules and social sanctions for unsustainable consumption behavior, (future) generations who could benefit from collective actions are different from (current) generations who should adopt sustainable behaviors, there are no affordable alternative technologies to achieve the desired consumption level for everybody, some (often repeated) individual actions, characterized by (often large) opportunity costs, might not produce any (local) benefit or could produce (only) international benefits. Consequently, scholars should also focus on global environmental agreements that enhance the adherence to the SS egalitarian perspective, although some ethical problems might remain.

Note that there is a tight relationship between religious environmental ethics and the secular environmental ethics discussed in this paper. For example, an increase in a resembles the parsimony that is valued by Islam, whereas stewardship in Judaism is similar to $\zeta=1$, and equilibrium in Buddhism and Hinduism is similar to an equal distribution of resources between current and future generations. Moreover, this paper highlights the main dilemma (i.e., achieving human continuity vs. reducing human pain) behind the sustainability issue. Finally, environmental ethics is treated as political economy in this paper (i.e., whether environmental precepts and principles can promote desirable pro-environmental behavior).

Future development of the model in this study could analyze the distribution of costs for sustainability within countries (e.g., by environmental sociology and economics) and the conditions required to achieve a self-enforcing global agreement (e.g., by environmental jurisprudence and economics). 


\section{Data availability}

The datasets analyzed during this study come from public sources, as detailed in text: they are available from the corresponding author on reasonable request.

Received: 11 February 2020; Accepted: 9 April 2020;

Published online: 02 June 2020

\section{References}

Aznar-Marquez J, Ruiz-Tamarit JR (2016) Environmental pollution, sustained growth, and sufficient conditions for sustainable development. Economic Model 54:439-449

Basedau M et al. (2018) The multidimensional effects of religion on socioeconomic development: a review of the empirical literature. J Economic Surv 32:1106-1133

Bezin E (2019) The economics of green consumption, cultural transmission and sustainable technological change. J Economic Theory 181:497-546

Chen W, Zang W, Fan W, Yu G (2018) Optimise emission reduction commitments for international environmental agreements. Mitigation Adapt Strateg Glob Change 23:1367-1389

Diprose K, Liu C, Valentine G, Vanderbeck RM, McQuaid K (2019) Caring for the future: climate change and intergenerational responsibility in China and the UK. Geoforum 105:158-167

Franco MPV, Gaspard M, Mueller T (2019) Time discounting in Harold Hotelling's approach to natural resource economics; the unsolved ethical question. Ecol Econ 163:52-60

Iyer G, Calvin K, Clarke L, Edmonds J, Hultman N, Hartin C, McJeon H, Aldy J, Pizer W (2018) Implications of sustainable development considerations for comparability across nationally determined contributions. Nat Clim Change 8:124-129

Jain P, Jain P (2013) Sustainability assessment index: a strong sustainability approach to measure sustainable human development. Int J Sustain Dev World Ecol 20:116-122

Kallis G (2011) In defense of de-growth. Ecol Econ 70:873-880

Kallis G, Kerschner C, Martinez-Alier J (2012) The economics of de-growth. Ecol Econ 84:172-180

Kenter JO, Raymond CM, Van Riper CJ, Azzopardi E, Brear MR, Calcagni F, Christie I, Christie M, Fordham A, Gould RK, Ives CD (2019) Loving the mess: navigating diversity and conflict in social values for sustainability. Sustain Sci 14:1439-1461

Kim RE, Bosselmann K (2015) Operationalizing sustainable development: ecological integrity as a grundnorm of international law. Rev Eur, Comp Int Environ Law 24:194-208

Lenzi D (2017) Relativism, ambiguity and environmental virtues. Environ Values 26:91-109

Mauerhofer V (2019) Activities of environmental convention-secretariats: laws, functions and discretions. Sustainability 11:art. no. 3116

Menning N (2016) Reading nature religiously, Worldviews: Environment. Cult, Relig 20:169-188

Riley S (2016) Architectures of intergenerational justice: human dignity, international law, and duties to future generations. J Hum Rights 15:272-290

Rockstrom J, Gaffney O, Rogelj J, Meinshausen M, Nakicenovic N, Schellnhuber HJ (2017) A roadmap for rapid decarbonization. Science 355:1269-1271

Santarius T, Soland M (2018) How technological efficiency improvements change consumer preferences: towards a psychological theory of rebound effects. Ecol Econ 146:414-424

Schaffartzik AA, Mayer A, Eisenmenger N, Krausmann F (2016) Global patterns of metal extractivism 1950-2010: providing the bones for the industrial society's skeleton. Ecol Econ 122:101-110

Schlör H, Fischer W, Hake JF (2015) The system boundaries of sustainability. J Clean Prod 88:52-60
Shutters ST (2016) Interdependent preferences and prospects for global sustainability. Int J Sustainability Policy Pract 12:25-39

Skillington T (2019) Changing perspectives on natural resource heritage, human rights, and intergenerational justice. Int J Hum Rights 23:615-637

Spahn A (2018) "The first generation to end poverty and the last to save the planet"? Western individualism, human rights and the value of nature in the ethics of global sustainable development. Sustainability 10:art. no. 1853

Steffen W, Richardson K, Rockström J, Cornell SE, Fetzer I, Bennett EM, Biggs R, Carpenter SR, De Vries W, De Wit CA, Folke C (2015) Planetary boundaries: guiding human development on a changing planet. Science 347:1259855

Tran M (2016) A general framework for analyzing techno-behavioral dynamics on networks. Environ Model Softw 78:225-233

Van den Bergh JCJM (2010) Externality or sustainability economics? Ecol Econ 69:2047-2052

Van den Bergh JCJM (2011) Environment versus growth-a criticism of "degrowth" and a plea for "a-growth". Ecol Econ 70:881-890

White L (1967) The historical roots of our ecologic crisis. Science 155/3767:1203-1207

Zagonari F (2015) Technology improvements and value changes for sustainable happiness: a cross-development analytical model, Sustainability. Science 10:687-698

Zagonari F (2018) Responsibility, inequality, efficiency, and equity in four sustainability paradigms: insights for the global environment from a crossdevelopment analytical model. Environ Dev Sustain. https://doi.org/10.1007/ s10668-018-0159-2

Zagonari F (2019a) Only religious ethics can help achieve global environmental sustainability. Environ Dev Sustain. https://doi.org/10.6092/unibo/amsacta/6214

Zagonari F (2019b) (Moral) philosophy and (moral) theology can function as (behavioral) science: a methodological framework for interdisciplinary research. Quality Quantity. 53:3131-3158. https://doi.org/10.1007/s11135019-00930-5

Zagonari F (2020) Comparing religious environmental ethics to support efforts to achieve local and global sustainability: empirical insights based on a theoretical framework. Sustainability 12:art. no. 2590

\section{Competing interests}

The author declares no competing interests.

\section{Additional information}

Supplementary information is available for this paper at https://doi.org/10.1057/s41599020-0467-7.

Correspondence and requests for materials should be addressed to F.Z.

Reprints and permission information is available at http://www.nature.com/reprints

Publisher's note Springer Nature remains neutral with regard to jurisdictional claims in published maps and institutional affiliations.

(c) (i) Open Access This article is licensed under a Creative Commons Attribution 4.0 International License, which permits use, sharing, adaptation, distribution and reproduction in any medium or format, as long as you give appropriate credit to the original author(s) and the source, provide a link to the Creative Commons license, and indicate if changes were made. The images or other third party material in this article are included in the article's Creative Commons license, unless indicated otherwise in a credit line to the material. If material is not included in the article's Creative Commons license and your intended use is not permitted by statutory regulation or exceeds the permitted use, you will need to obtain permission directly from the copyright holder. To view a copy of this license, visit http://creativecommons.org/ licenses/by/4.0/.

(C) The Author(s) 2020 